\title{
Asymmetric Lateral Ventricles-A Tale of Two Cases
}

\author{
Nakul Pahwa ${ }^{1}$ \\ ${ }^{1}$ Department of Neurosurgery, Nilratan Sircar Medical College and \\ Hospital, Kolkata, West Bengal, India
}

\author{
Address for correspondence Nakul Pahwa, MCh, A-11, Street \\ No.7, Kundan Nagar, Near Grover Hospital, New Delhi 110092, India \\ (e-mail: dl7sad6246@gmail.com).
}

Indian J Neurotrauma 2022;19:47-48.

\begin{abstract}
Keywords

- asymmetry

- lateral ventricles

- asymmetry of the

lateral ventricles

Asymmetry of the lateral ventricles is not an uncommon finding. On one end, it is a predictor of intracranial pathology, and on the other, it can represent a normal variant. It needs to be appropriately investigated. In this case report, we presented two cases of asymmetric lateral ventricles, their presentation, progression and management.
\end{abstract}

\section{Introduction}

The right and left lateral ventricles are the largest parts of the ventricular system of the brain. The right and left sides are separated by a thin midline septum called the septum pellucidum. On each side of the septum, lateral ventricles are like a mirror image of each other, and most of the time, they are identical and symmetrical. However, asymmetric lateral ventricles (ALV) or unilateral hydrocephalus are not rare. ${ }^{1}$ The asymmetry can be caused by a unilateral intra- or extraventricular space occupying lesion or disease such as Parkinson's disease. ${ }^{2}$ ALV cases should be evaluated for presence of hydrocephalus, and most common indices and measurement methods include Evan's index and callosal angle. ${ }^{3}$ In trauma cases, they are predictors of midline shift in case of extradural/subdural hematomas or contusions. Some studies also have linked asymmetry to rightor left-handedness. ${ }^{4}$ However, we encounter ALV more frequently in the normal population. ${ }^{5}$ If the asymmetry is noticeable and obvious in an otherwise normal MRI, it is usually reported as a normal variant. ${ }^{6}$

In this article, we presented two cases of ALV with different presentation, progression, and management.

\section{Case Discussion}

\section{First Case}

A 16-year-old male patient presented to ER with history of physical assault by an iron rod to the right side of his face and head. On presentation, he was vitally stable and

published online

October 27, 2021
DOI https://doi.org/ $10.1055 / \mathrm{s}-0041-1734343$ ISSN 0973-0508 neurologically intact. First CT brain showed mild asymmetry of ventricles. He was advised admission, but he denied. He came back after 12 hours with altered sensorium, Glasgow coma scale (GCS) score of E3V3M5, episodes of vomiting and dense hemiplegia (power grade 0/5) of left side of body with facial palsy. Repeat CT scan showed hypodense regions involving right temporal, insular, head of caudate, and internal capsule regions with compressed right lateral ventricle, midline shift to left and dense middle cerebral artery (MCA) sign on the right side ( - Fig. 1 ).

He was shifted to ICU and started on antiedema measures and double antiplatelets. Gradually, within a few hours, GCS score improved to E4V5M6, and left side hemiparesis also improved (power grade $2 / 5$ ). MRI brain with angiography revealed large area of diffusion restriction in right MCA territory and nonvisualization of right internal carotid artery (ICA) and MCA. Carotid Doppler showed normal right common carotid artery (CCA) and cervical ICA.

Stroke profile showed normal Hb electrophoresis, sickle cell screen, antinuclear antibody (ANA), prothrombin time (PT)/activated partial thromboplastin time (APTT), and international normalized ratio (INR). Only his erythrocyte sedimentation rate (ESR) was raised $(112 \mathrm{~mm})$. His hemiparesis gradually improved, and the patient did not attend follow-up angiography.

\section{Second Case}

A 21-year-old male patient presented to ER with history of road traffic accident. He was riding a motorcycle without helmet which collided with a four-wheeler. On presentation, he

\footnotetext{
(C) 2021. Neurotrauma Society of India.
}

This is an open access article published by Thieme under the terms of the Creative Commons Attribution-NonDerivative-NonCommercial-License, permitting copying and reproduction so long as the original work is given appropriate credit. Contents may not be used for commercial purposes, or adapted, remixed, transformed or built upon. (https://creativecommons.org/licenses/by-nc-nd/4.0/).

Thieme Medical and Scientific Publishers Pvt. Ltd. A-12, 2nd Floor, Sector 2, Noida-201301 UP, India 


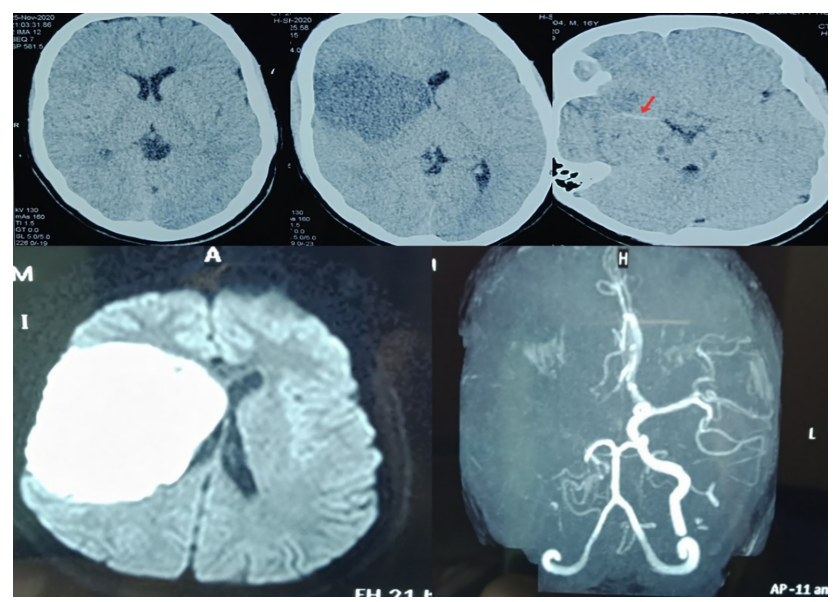

Fig. 1 Nonenhanced CT on presentation showing asymmetry of lateral ventricles. Repeat $\mathrm{CT}$ after 12 hours showing area of infarct along with middle cerebral artery (MCA) dense sign. Diffusion-weighted imaging (DWI) MRI showing area of restriction. Magnetic resonance angiography (MRA) with nonvisualization of right internal carotid artery (ICA) and MCA.

was vitally stable and neurologically intact. CT brain showed asymmetry of lateral ventricles and dilated temporal horns. He was advised observation in ICU. MRI brain with angiography was normal (-Fig. 2).

\section{Discussion}

ALV is a common finding in daily practice. ${ }^{1}$ It presents a challenge to the neurosurgeon, as it can either be linked to many intracranial and intraventricular pathologies or it may be a normal variant. ALV without other pathological findings on MRI is mostly caused by the off-midline septum pellucidum. ${ }^{6}$ Toth et al showed that ALV was a precursor of midline shift in trauma patients and noted that ventricles respond to unilateral pressure gradient before the midline shift.?

In the first case discussed here, ALV was predictor of posttraumatic stroke despite first scan not showing any other abnormality. It could have been life-threatening had the patient not presented the next day. On the other hand, in the second case, we could easily rule out any pathological cause by appropriate investigations, and consider it as normal variant of ALV.

The role of MRI/magnetic resonance angiography (MRA) in cases of ALV with no neurological deficits is a matter of debate. The importance is in differentiating unilateral

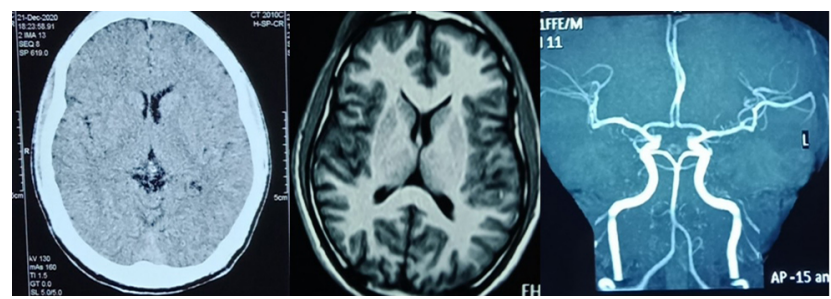

Fig. 2 Nonenhanced CT showing asymmetric ventricles. Normal MRI brain and angiography.

hydrocephalus (UH) from ALV. UH is defined as enlargement of a lateral ventricle and represents a more serious clinical entity, with a higher ventricle-brain ratio (VBR) than ALV. In the Turkish study, 3.5\% patients had underlying tumors on MRI which were occult on CT, even in retrospect. ${ }^{1}$

In conclusion, it requires a neurosurgeon to be vigilant enough to not rule out asymmetry of ventricles as normal without workup. It would be ideal to keep such a patient in hospital for some duration, even if the patient is neurologically intact, and do a repeat scan after 12 to 24 hours to rule out any abnormality.

\section{Conflict of Interest}

None declared.

\section{References}

1 Kiroglu Y, Karabulut N, Oncel C, Yagci B, Sabir N, Ozdemir B. Cerebral lateral ventricular asymmetry on CT: how much asymmetry is representing pathology? Surg Radiol Anat 2008;30(3):249-255

2 Huang $\mathrm{X}$, Lee $\mathrm{YZ}$, McKeown $\mathrm{M}$, et al. Asymmetrical ventricular enlargement in Parkinson's disease. Mov Disord 2007;22(11):1657-1660

3 LeMay M, New PF. Radiological diagnosis of occult normal-pressure hydrocephalus. Radiology 1970;96(2):347-358

4 Erdogan AR, Dane S, Aydin MD, Ozdikici M, Diyarbakirli S. Sex and handedness differences in size of cerebral ventricles of normal subjects. Int J Neurosci 2004;114(1):67-73

5 Shapiro R, Galloway SJ, Shapiro MD. Minimal asymmetry of the brain: a normal variant. AJR Am J Roentgenol 1986;147(4):753-756

6 Arslan G, Ozdemir NBU. Quantification of the asymmetry between right and left cerebral lateral ventricles by indexing methods. Neurol India 2020;68(6):1367-1373

7 Tóth A, Schmalfuss I, Heaton SC, et al. Lateral ventricle asymmetry predicts midline shift in severe traumatic brain injury. J Neurotrauma 2015;32(17):1307-1311 